\title{
Influence of Advanced Injection Timing and Fuel Additive on Combustion, Performance, and Emission Characteristics of a DI Diesel Engine Running on Plastic Pyrolysis Oil
}

\author{
Ioannis Kalargaris, Guohong Tian, and Sai Gu \\ Faculty of Engineering and Physical Sciences, University of Surrey, Guildford GU2 7XH, UK \\ Correspondence should be addressed to Sai Gu; sai.gu@surrey.ac.uk
}

Received 26 October 2016; Accepted 25 December 2016; Published 15 February 2017

Academic Editor: Constantine D. Rakopoulos

Copyright (C) 2017 Ioannis Kalargaris et al. This is an open access article distributed under the Creative Commons Attribution License, which permits unrestricted use, distribution, and reproduction in any medium, provided the original work is properly cited.

\begin{abstract}
This paper presents the investigation of engine optimisation when plastic pyrolysis oil (PPO) is used as the primary fuel of a direct injection diesel engine. Our previous investigation revealed that PPO is a promising fuel; however the results suggested that control parameters should be optimised in order to obtain a better engine performance. In the present work, the injection timing was advanced, and fuel additives were utilised to overcome the issues experienced in the previous work. In addition, spray characteristics of PPO were investigated in comparison with diesel to provide in-depth understanding of the engine behaviour. The experimental results on advanced injection timing (AIT) showed reduced brake thermal efficiency and increased carbon monoxide, unburned hydrocarbons, and nitrogen oxides emissions in comparison to standard injection timing. On the other hand, the addition of fuel additive resulted in higher engine efficiency and lower exhaust emissions. Finally, the spray tests revealed that the spray tip penetration for PPO is faster than diesel. The results suggested that AIT is not a preferable option while fuel additive is a promising solution for long-term use of PPO in diesel engines.
\end{abstract}

\section{Introduction}

Human developments have been coupled with the evolution of the extraction, use, and disposal of natural resources. The way in which waste is disposed has changed dramatically over the last decades, as have attitudes towards waste reduction, reuse, and recycling, as well as recovering energy from waste. Energy from waste can be recovered through the pyrolysis process which converts the waste into oil and gas. Plastic is a type of waste that is plentiful and can be used effectively due to the high energy content. The conversion products can be used in internal combustion engines to produce power and heat. The effect of plastic pyrolysis oil (PPO) in diesel engines has been studied by various authors mainly in blends with diesel in single cylinder engines [1-8]. The investigations showed that diesel engines can run stable on medium PPOdiesel blend rates but with lower brake thermal efficiency and higher exhaust emissions (NOx, UHC, and CO). Due to the lower quality of the PPO in comparison with diesel fuel, one or a combination of the following ways/processes has to be applied in order to achieve stable engine performance at higher PPO-diesel blend rates or without diesel: upgrade of the oil, modification of the engine, and addition of fuel additives.

One of the most important engine parameters is the injection timing. The effect of injection timing (IT) in alternative fuels based on waste plastics has been studied in single cylinder diesel engines and the results are promising. Mani and Nagarajan [9] have investigated the effect of retarded IT on diesel engines running on waste plastic pyrolysis oil (PPO). The results showed that the unburned hydrocarbon, oxides of nitrogen, and carbon monoxide emissions are decreasing while the carbon dioxide emission and brake thermal efficiency are increasing. Another research on a fuel blend of $20 \%$ tyre pyrolysis oil and $80 \%$ of jatropha ester revealed that the advanced IT results in lower fuel consumption, carbon monoxide, unburned hydrocarbon, and particulate matter emissions whereas the oxides of nitrogen are increasing 
[10]. Finally, Wamankar and Murugan conducted a research using a blend of $90 \%$ diesel and $10 \%$ waste tyre oil. The results showed that the brake thermal efficiency and oxides of nitrogen emission were higher while the fuel consumption, carbon monoxide, and unburned hydrocarbon emissions were lower when running on advanced IT [11].

On the other hand, fuel additives are preferable in the case of good quality oil that needs to boost a property such as cetane number or lubricity in order to improve the engine performance. Diethyl ether is an organic compound with high cetane number, which has been used in research as a cetane number improver. Devaraj et al. [12] investigated the effect of diethyl ether on waste plastic pyrolysis oil used as fuel for a single cylinder diesel engine. The results showed reduction in ignition delay period, heat release rate, cylinder peak pressure, carbon monoxide, carbon dioxide, and oxides of nitrogen emissions while the brake thermal efficiency and unburned hydrocarbon emissions were increased. Another research on tyre pyrolysis oil blended with diethyl ether on a single cylinder research engine revealed that the ignition delay period, unburned hydrocarbon, and oxides of nitrogen emissions are reducing with the addition of diethyl ether whereas the brake thermal efficiency is increasing [13].

What has not been investigated yet in larger diesel engines is the advanced IT by using PPO in blends with diesel and the use of a fuel additive to improve the engine's performance when running on PPO. Moreover, the spray characteristics from oil that derives from the pyrolysis of plastics have not been determined yet. Our previous investigation on the use of PPO in a four-cylinder diesel engine revealed that there is longer ignition delay and higher heat release rate (HRR) in comparison with diesel [14]. In order to reduce the ignition delay period and achieve lower HRR the advanced IT and a commercial fuel additive were tested. An additional investigation on the spray characteristics of the PPO was carried out in parallel with the engine tests to provide more insight knowledge for engine control strategy optimisation.

\section{Materials and Methods}

2.1. Conversion Process and Fuel Properties. The conversion of the waste plastics into oil, gas, and char is taking place in the pyrolysis plant. More specifically, the plant consists of the primary and secondary chambers, where the plastics are purged with carbon dioxide to ensure that no oxygen is transferred into the next chamber which is the conversion chamber. The conversion chamber is maintained at a temperature of $900^{\circ} \mathrm{C}$ and the plastics are converted into gas and char. Finally, the gas is passed into a condenser, where it is cooled, and pyrolysis oil is separated out. The basic properties of PPO benchmarked with diesel and the test methods which were used to determine them are presented in Table 1. More information can be found about the plastics, produced oil, and gas composition in our previous publication [14].

Although the precise cetane number of the PPO is not provided in the table, it was clearly observed from our previous investigation that the combustion delay was considerably extended with higher PPO blending ratio, which suggests that PPO has lower cetane number than diesel [14].
TABLE 1: PPO and diesel properties.

\begin{tabular}{lccc}
\hline Property & Method & PPO & Diesel \\
\hline $\begin{array}{l}\text { Density@15 }{ }^{\circ} \mathrm{C}(\mathrm{kg} / \mathrm{l}) \\
\text { Kinematic }\end{array}$ & ASTM D4052 & 0.9813 & 0.8398 \\
viscosity@40 ${ }^{\circ} \mathrm{C}(\mathrm{cSt})$ & IP 71 & 1.918 & 2.62 \\
Flash point $\left({ }^{\circ} \mathrm{C}\right)$ & ASTM D93 & 13 & 59.5 \\
Aromatic content (\%) & IP 391 & 65.5 & 29.5 \\
Acid number (mg & IP 139 & 41 & 0 \\
KOH/g) & ASTM D240 & 38.300 & 42.900 \\
LHV (M)/kg) & ASTM D6304 & 1190 & 65 \\
Water content (mg/kg) & 0.166 & $<0.001$ \\
$\begin{array}{l}\text { Ash content (wt.\%) } \\
\text { Carbon residue (wt.\%) }\end{array}$ & ASTM D4530 & 4.83 & $<0.01$ \\
$\begin{array}{l}\text { Hydrogen content } \\
\text { (wt.\%) }\end{array}$ & ASTM D5291 & 8.5 & 13.38 \\
Carbon content (wt.\%) & ASTM D5291 & 87.9 & 86.57 \\
$\begin{array}{l}\text { Oxygen content (wt.\%) } \\
\text { Sulphur content (wt.\%) }\end{array}$ & ASTM D5622 & 3.3 & 0.05 \\
$\begin{array}{l}\text { Nitrogen content } \\
\text { (mg/kg) }\end{array}$ & ASTM D5453 & 0.155 & 0.0014 \\
\hline
\end{tabular}

TABle 2: Fuel additive composition.

\begin{tabular}{lc}
\hline Compound & Quantity (\% wt) \\
\hline Petroleum naphtha & $29-38$ \\
2-Ethylhexanol & $16-24.25$ \\
2-Ethylhexyl nitrate & $7.75-15.5$ \\
1,2,4-Trimethylbenzene & $7.75-15.5$ \\
1,3,5-Trimethylbenzene & $0.775-3.875$ \\
Propylene glycol ether & $0.775-3.875$ \\
Xylene & $0.8-4$ \\
Trimethylbenzene & $7.75-15.5$ \\
1,2,3-Trimethylbenzene & $0.8-4$ \\
Soy methyl ester & 5 \\
\hline
\end{tabular}

In order to reduce the ignition delay period, the cetane number of the fuel should be increased. One of the main cetane number improver additives manufactured today is the 2-ethylhexyl nitrate (2-EHN). It should be mentioned that 2 -EHN can reduce lubricity so it is important to add a lubricant additive. Table 2 shows the composition of the commercial fuel additive that was used in the experiments. The commercial fuel additive was chosen according to the primary functions of reducing the ignition delay period (cetane number improver), increasing the injectors' lubrication, and cleaning and removing the deposits from the combustion chambers.

2.2. Diesel Engine Experimental Setup. The diesel engine that is used to conduct the experiments is a four-cylinder, direct injection, turbocharged water-cooled diesel engine. Figure 1 presents the schematic layout of the experimental setup and Table 3 shows the engine's specifications. The engine is mated to an alternator and then to a load bank to control the load of 


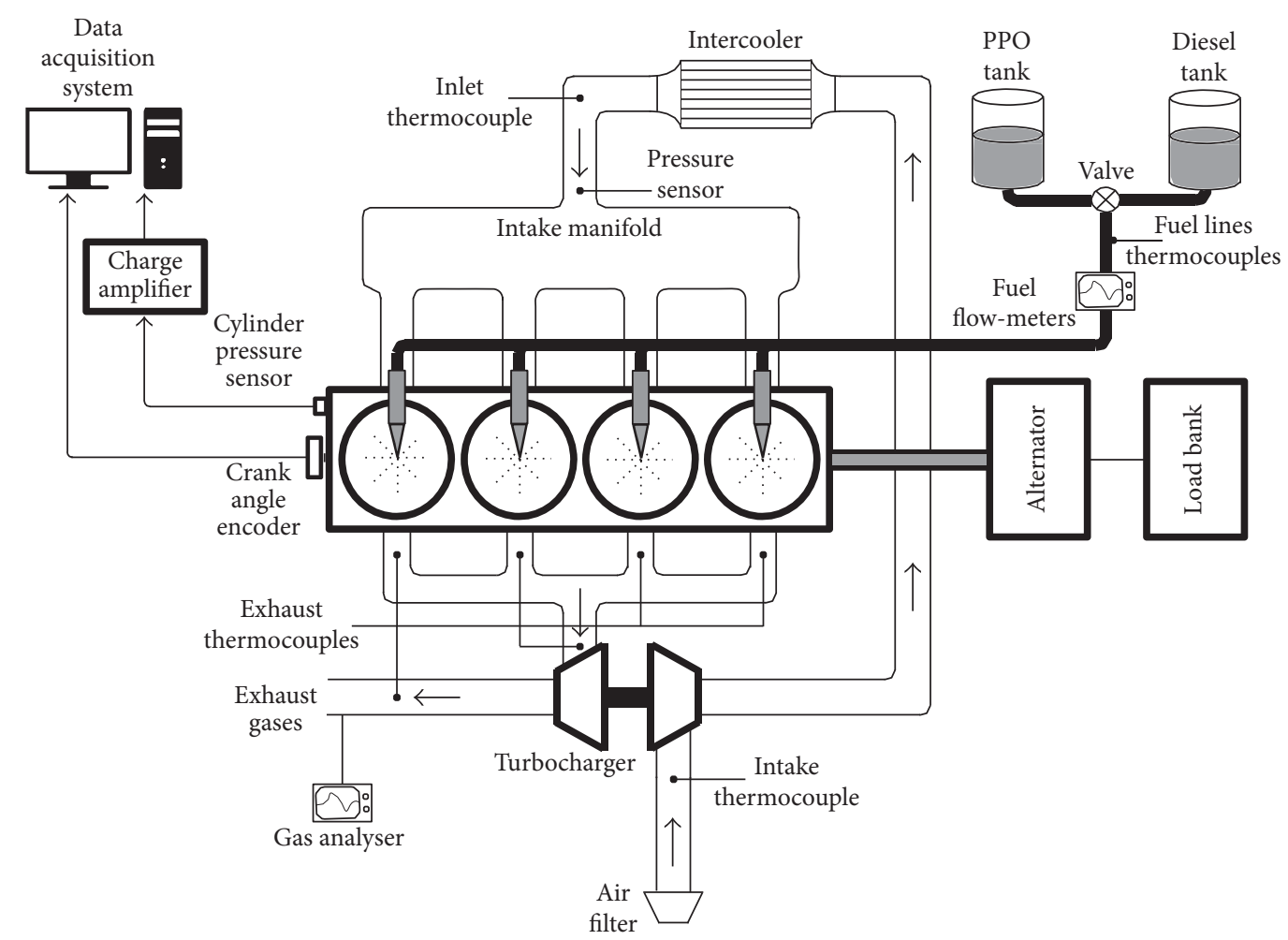

FIGURE 1: Schematic layout of the experimental setup.

TABLE 3: Test engine specifications.

\begin{tabular}{lc}
\hline Brand & AKSA \\
\hline Model & A4CRX46TI \\
Compression ratio & $17: 1$ \\
Displacement & 4.581 \\
Rated power & $68 \mathrm{~kW}$ \\
Rated speed & $1500 \mathrm{rpm}$ \\
Injection pressure & $240 \mathrm{bar}$ \\
Bore & $110 \mathrm{~mm}$ \\
Stroke & $125 \mathrm{~mm}$ \\
\hline
\end{tabular}

the engine. Furthermore, several sensors are used to monitor the engine's performance and a gas analyser that can measure the exhaust emissions ( $\mathrm{CO}, \mathrm{CO}_{2}, \mathrm{NOx}$, and $\mathrm{UHC}$ ) as it can be seen in Figure 1.

The engine was started and run for 30 minutes on diesel to warm-up and stabilise the oil and coolant temperatures and then it was switched on the desired fuel blend and run for 5 minutes before the data acquisition was started. The flowmeter measurements, manifold pressure, temperatures, and exhaust emissions data were taken for a period of five minutes and the average values were calculated. As regards the combustion analysis, 100 consecutive cycles were acquired from the in-cylinder pressure sensor and the average was calculated. In addition, the heat release rate was calculated from (1) by using the in-cylinder pressure data and the crank angle encoder readings.

$$
\frac{d Q}{d \theta}=\frac{\gamma}{\gamma-1} p \frac{d V}{d \theta}+\frac{1}{\gamma-1} V \frac{d p}{d \theta},
$$

where $d Q / d \theta$ is the net heat release rate $\left(\mathrm{J} /{ }^{\circ} \mathrm{CA}\right), \gamma$ is the ratio of the specific heats, $p$ is the cylinder pressure $(\mathrm{Pa})$, and $V$ is the cylinder volume $\left(\mathrm{m}^{3}\right)$. In this study, a constant value of 1.35 was used for $\gamma$. After the end of the data acquisition, the engine was switched back to diesel and run for 30 minutes to flush out the fuel lines and the injection system from the pyrolysis oil.

2.3. Spray Test Experimental Setup. The spray characteristics tests were carried out on a constant volume, high pressure chamber. The chamber was equipped with two windows on two sides in order to have optical access for the spray visualization. Moreover, the background pressure of the chamber was controlled at 5 bar. The diagram in Figure 2 shows the experimental setup for the spray test rig.

The fuel injection system was composed of a fuel tank, a fuel pump that was able to adjust the injection pressure up to 500 bar, an injector, and an electronic control unit (ECU). The signal from the ECU triggers the injector and the high speed camera, achieving synchronization of the spray visualization. The injector used in the experiments was a single-hole solenoid injector. Two different nozzle holes' diameters of $0.12 \mathrm{~mm}$ and $0.18 \mathrm{~mm}$ were used in the 


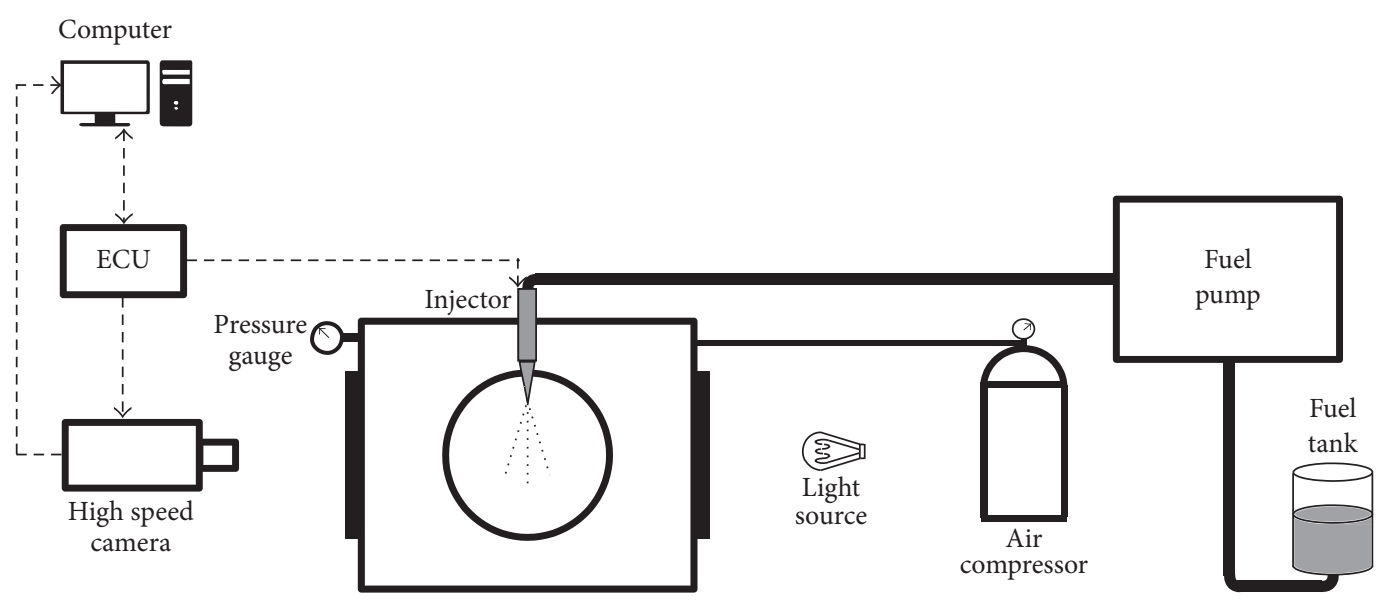

FIGURE 2: Schematic layout of the spray test rig.

experiments. Moreover, two different injection pressures of 300 bar and 450 bar were tested at every nozzle diameter size. The reason that the injection pressures were not tested at higher values is because the PPO is going to be used in diesel engines for stationary power and heat generation, which are usually equipped with mechanical injectors.

For the spray macroscopic characteristic investigation (spray tip penetration, spray cone angle, and spray area) a light source was used on one side and a high speed camera on the other. The high speed camera (Dantec Dynamics, Speedsence) was set up to record the spray images with an imaging speed of 60,000 frames per second and resolution of $256 \times 256$ pixels. In order to ensure the reliability of the results every experiment was repeated five times on each test condition. After that, the images were processed for further analysis of the spray characteristics. A program was written in MATLAB software, where a batch of spray images was able to get analysed at once and provide the spray tip penetration, spray cone angle, and spray area versus the time after the start of injection.

\section{Results and Discussion}

3.1. Advanced Injection Timing. In this section are presented and discussed the experimental results obtained from the engine by running on advanced IT (AIT) with a blend of $75 \%$ plastic pyrolysis oil and 25\% diesel (PPO 75) at 75\% and $100 \%$ engine loads which represent 9.47 bar and 12.63 bar of BMEP, respectively. The results of AIT $\left(-23^{\circ} \mathrm{CA}\right.$ bTDC) are compared with the standard IT (SIT) operation $\left(-18^{\circ} \mathrm{CA}\right.$ bTDC). The investigation is focused on the combustion characteristics, engine performance, and exhaust emission analysis. Moreover, the spray characteristics of PPO are analysed and compared with diesel.

Figure 3 shows the cylinder pressure with crank angle at $75 \%$ load. It can be seen that the AIT results in much higher in-cylinder pressure in comparison with SIT. This behaviour can be explained due to the earlier start of combustion on smaller cylinder volume. More specifically, the peak cylinder pressure for PPO $75 \mathrm{AIT}$ at $75 \%$ load is advanced by $2.9^{\circ} \mathrm{CA}$ in

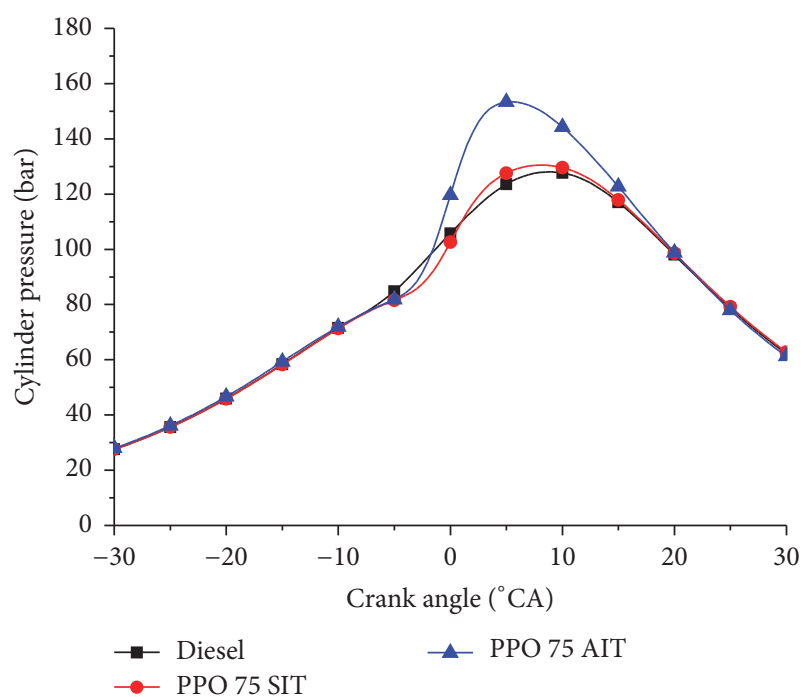

FIGURE 3: Variation of cylinder pressure with crank angle at $75 \%$ load.

comparison with the SIT operation. This result indicates that the ignition delay period of the PPO 75 AIT was even longer, resulting in better air-fuel mixing. The AIT is not sufficient to provide smaller ignition delay period due to the lower incylinder temperatures and pressures at the earlier ${ }^{\circ} \mathrm{CA}$ of the compression stroke.

The heat release rate (HRR) for the diesel and PPO 75 at SIT and AIT is presented in Figure 4. It can be seen from Figure 4 that the PPO 75 at AIT results in much higher HRR in comparison with SIT operation. The main reason for that is the longer ignition delay in the case of AIT. More specifically, the AIT of $5^{\circ} \mathrm{CA}$ degrees results in advance start of combustion of only $0.8^{\circ} \mathrm{CA}$ correlated to SIT. The longer ignition delay of AIT contributes to the better fuel atomisation and fuel-air mixing by allowing longer airfuel mixing time which will reduce the local rich-fuel zones where the equivalence ratio $(\varphi)$ is greater than 1 . Furthermore, 


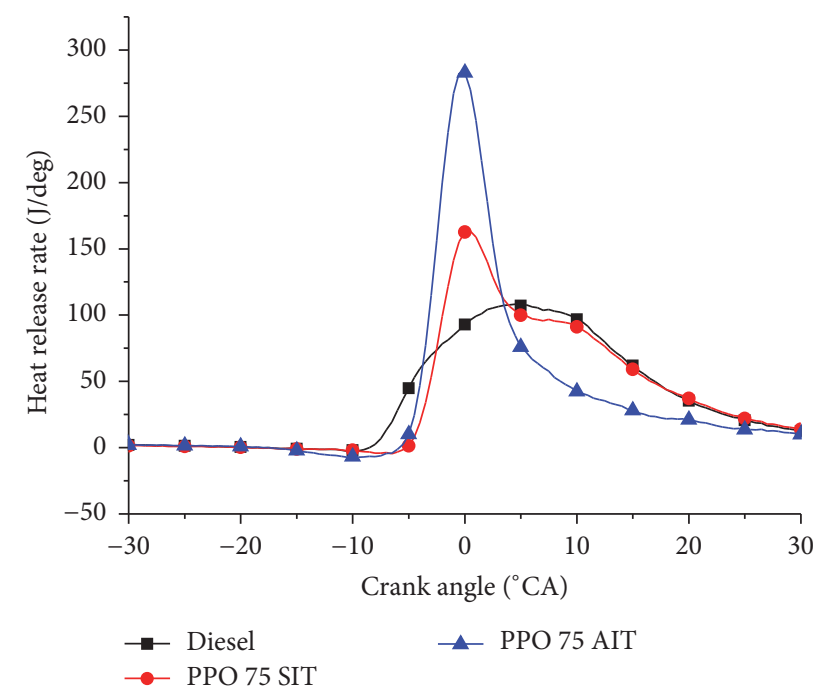

FIgURE 4: Variation of heat release rate with crank angle at 75\% load.

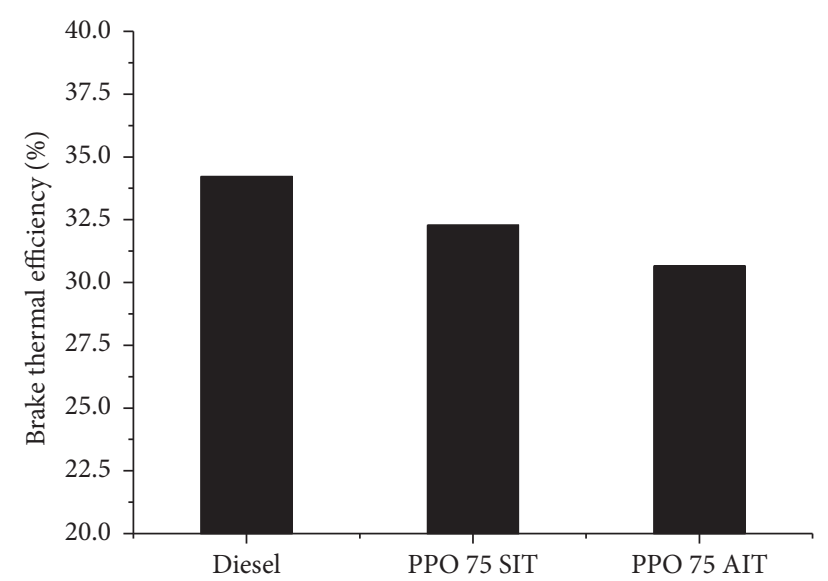

FIgURE 5: Brake thermal efficiency for diesel, PPO 75 SIT, and PPO 75 AIT.

fuels with high aromatic content as PPO tend to have higher adiabatic flame temperature because of the ring structure. The high adiabatic flame temperature results in higher heat release rate $[14,15]$. Consequently, the higher portion of premixed combustion resulted in more violent combustion and higher HRR and in-cylinder peak pressure.

Figure 5 shows the brake thermal efficiency for diesel, PPO 75 SIT, and PPO 75 AIT at 75\% load. It can be observed that the BTE is reducing from $32.3 \%$ on PPO 75 SIT operation to $30.7 \%$ on PPO 75 AIT. The main reason for the lower BTE is the longer ignition delay period which contributes to the increase of the fuel impingement on the cylinders walls. Consequently, the fuel that takes part in the effective combustion on the expansion stroke is less. Furthermore, the air-fuel mixing is enhanced by the longer ignition delay resulting in extremely high HRR early on the expansion stroke and less effective energy conversion of the heat to power on the cylinder. Finally, the lower BTE can

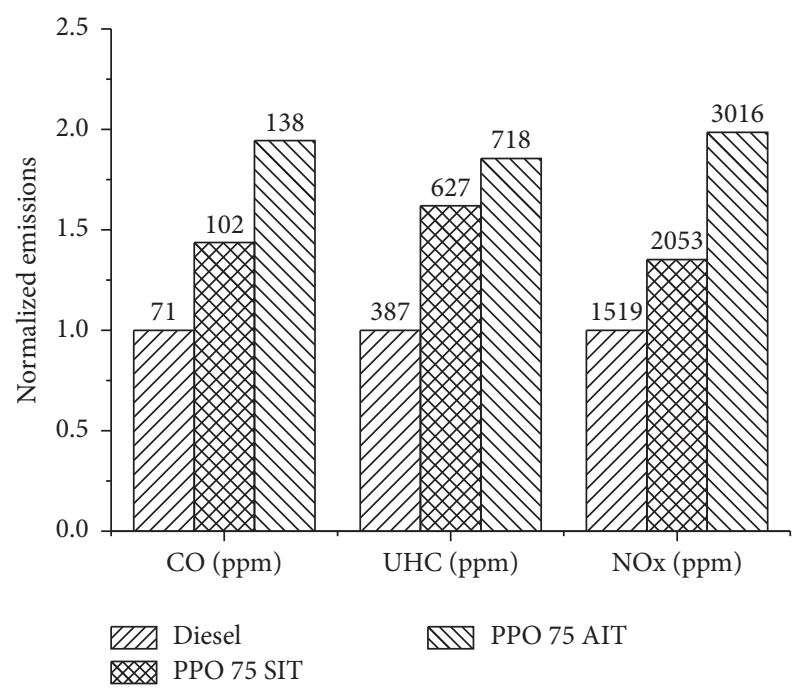

Figure 6: Normalized values of CO, UHC, and NOx emissions.

be explained due to the advanced start of combustion which results in increased heat transfer losses to the cylinders walls.

Figure 6 illustrates the normalized values of the carbon monoxide (CO), unburned hydrocarbons (UHC), and nitrogen oxides $(\mathrm{NOx})$ emissions for the engine operation on diesel, PPO 75 SIT, and PPO 75 AIT. The $Y$-axis (normalized emissions) shows the variation of the values in comparison with the diesel operation which has been set as the baseline point of 1 . Moreover, on the top of every column is written the actual value of the emissions.

It can be noticed from Figure 6 that the $\mathrm{CO}$ emissions increase considerably for the AIT operation (almost double in comparison to diesel with standard injection timing). $\mathrm{CO}$ emissions are mainly affected by the equivalence ratio and temperature, and it is a sign of incomplete combustion [15]. This result indicates that the combustion performance is more deficient and incomplete in the case of PPO 75 AIT. The longer ignition delay period results in the formation of local fuel-rich zones (crevices and cylinder walls) which are not able to oxidize to form $\mathrm{CO}_{2}$. The main reasons for the UHC emissions on the exhaust are the flame quenching and the undermixing or overleaning zones [15-17]. According to Figure 6 the UHC emissions increase dramatically in the case of AIT. It is believed that the longer ignition delay enhances the formation of local rich-fuel zones on the cylinder walls which are not able to burn completely. The elevated fuel consumption of the PPO 75 AIT also contributes to the increased UHC emissions. Finally, the NOx emissions are greatly affected by the change of the injection timing. More specifically, the NOx emissions of the PPO 75 AIT are almost double in comparison with diesel and 953 ppm higher with PPO 75 SIT. In combustion theory, there are three NOx production mechanisms: the thermal NO formation, the prompt $\mathrm{NO}$, and the NO formation from the nitrogen in the fuel $[15,18]$. In diesel engines the mechanism that produces the higher amount of NOx is mainly the thermal mechanism due to the elevated temperatures and high oxygen availability. The effect of the thermal mechanism is even higher in the case 


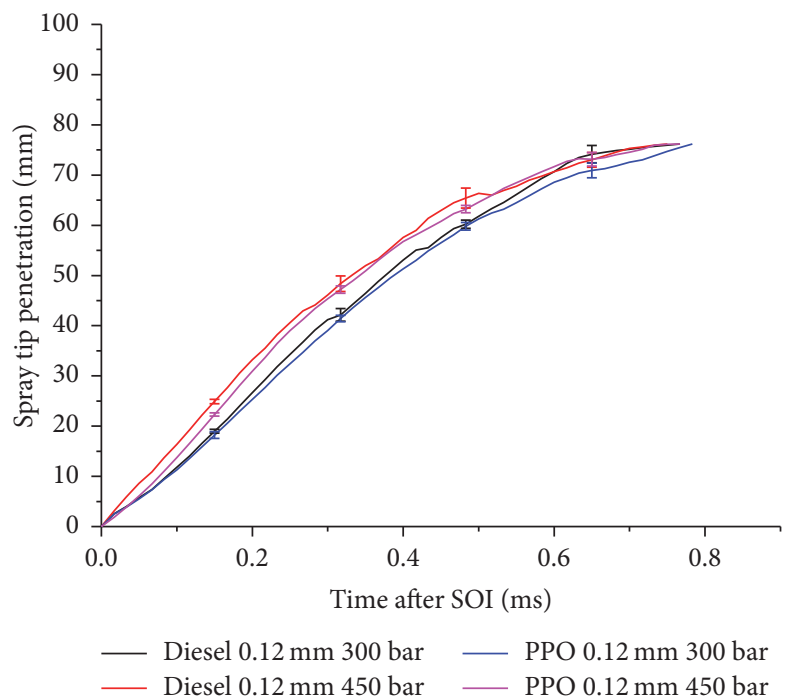

(a)

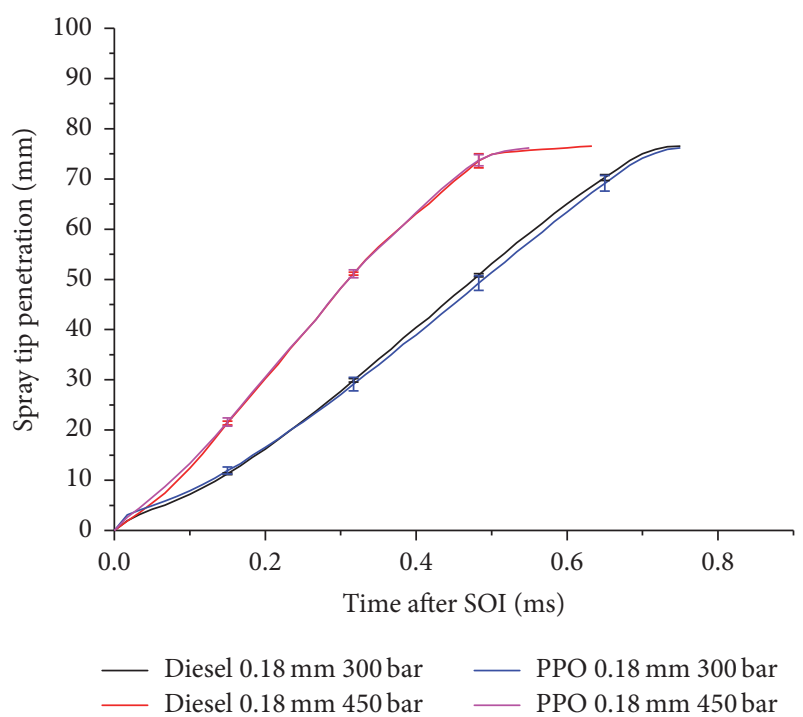

(b)

FIGURE 7: Variation of spray tip penetration with time for nozzle $0.12 \mathrm{~mm}$ (a) and $0.18 \mathrm{~mm}$ (b).

of the PPO 75 AIT due to the longer ignition delay. The longer ignition delay results in more homogeneous air-fuel mixture, higher in-cylinder pressures, in-cylinder temperatures, and heat release rates.

Figure 7 depicts the spray tip penetration for diesel and PPO for nozzle diameters of $0.12 \mathrm{~mm}$ and $0.18 \mathrm{~mm}$ and injection pressures of 300 bar and 450 bar (the bars show the standard error). The distance between the injector exit and the spray tip is defined as the spray tip penetration [19]. It can be seen that the impact of injection pressure is higher for the nozzle diameter of $0.18 \mathrm{~mm}$ in comparison with the $0.12 \mathrm{~mm}$. As regards the differences between the diesel and $\mathrm{PPO}$, it can be noticed that the spray tip penetration of PPO is faster for both 300 and 450 bar injection for the $0.12 \mathrm{~mm}$ nozzle diameter. On the other hand, the spray tip penetration is almost identical for the nozzle of $0.18 \mathrm{~mm}$ diameter. The results from the macroscopic spray characteristics analysis suggest that PPO has longer penetration, which means more chance to wet the wall which will lead to higher $\mathrm{CO}$ and UHC emissions. In addition to advanced injection, the in-cylinder pressure is lower at the time of injection, which will enhance the wall-wetting effect. It seems that the use of a larger hole at lower injection pressure would help; however it will increase particle emissions.

3.2. Fuel Additive. In this section are presented the experimental results obtained from the engine by running on $\mathrm{PPO}$ 75 blended with a commercial fuel additive at two different ratios of $1: 80$ and $1: 40$. The composition of the fuel additive is presented in Table 2. The blend results are compared with diesel and PPO 75 operation at 85\% load which represents 10.74 bar of BMEP. The investigation is focused on the combustion characteristics, engine performance, and exhaust emission analysis.

Figure 8 illustrates the cylinder pressure with crank angle for diesel, PPO 75, and PPO 75 with two different ratios of

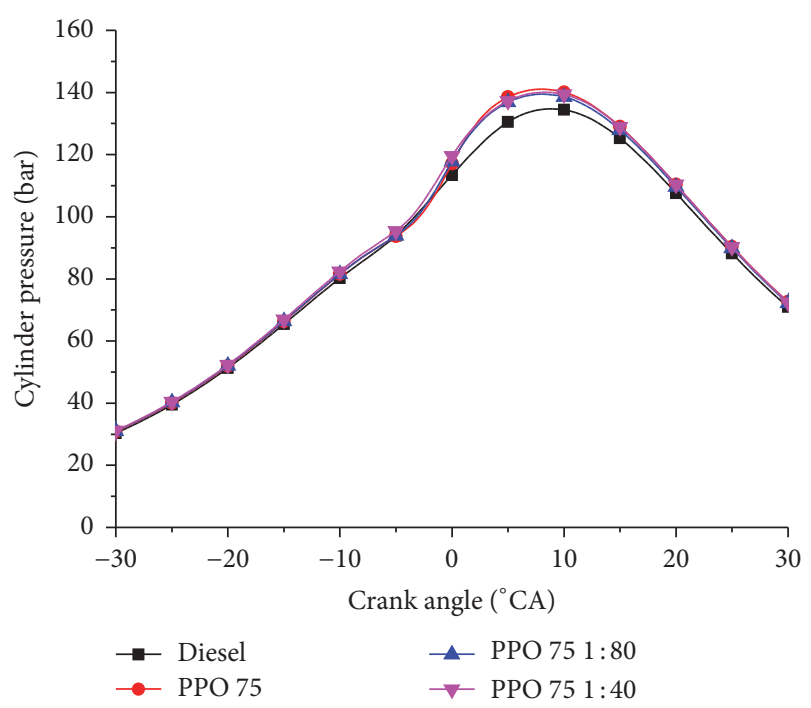

FIGURE 8: Variation of cylinder pressure with crank angle at $85 \%$ load.

fuel additive at $85 \%$ load. It can be observed that the cylinder pressure reaches higher values in the case of PPO operations in comparison with diesel. The main reason for that is the longer ignition delay of PPO 75 that results in later start of combustion during the compression stroke (closer to the TDC). Moreover, the longer ignition delay enhances the airfuel mixing producing faster expansion of the combustion. The fuel additive addition marginally reduces the ignition delay period and the peak cylinder pressure. This happens due to the cetane improver that it is contained in the fuel additive.

The HRR for diesel and PPO 75 fuel additive blends at $85 \%$ load is presented in Figure 9. It can be clearly seen that 


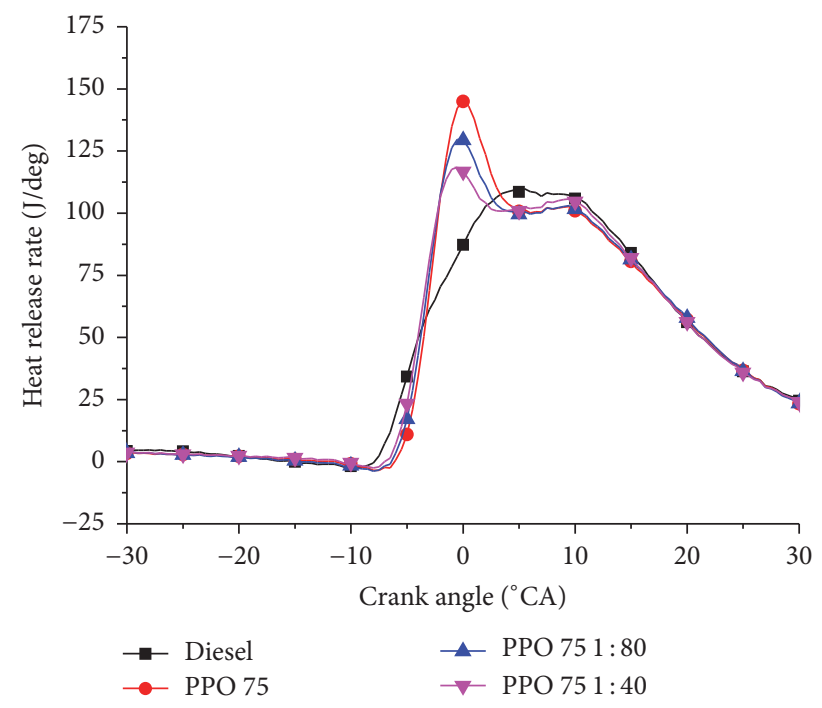

FIGURE 9: Variation of heat release rate with crank angle at $85 \%$ load.

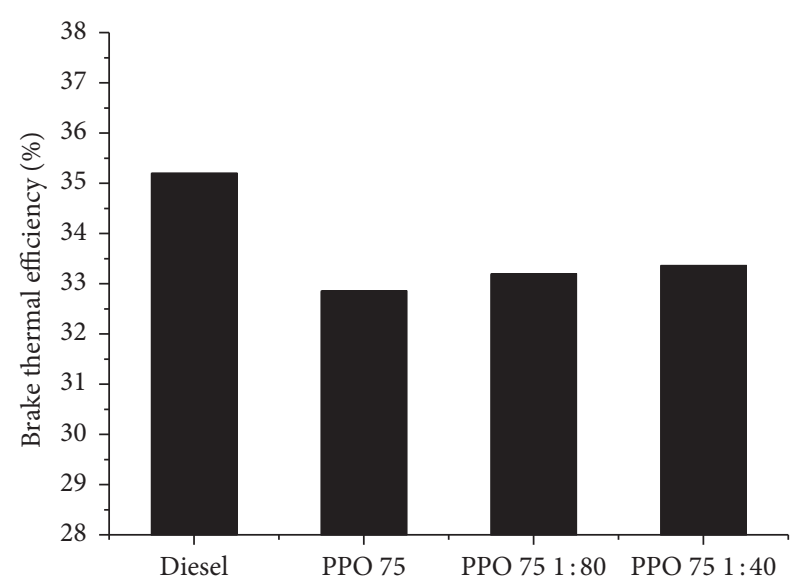

FIGURE 10: Variation of BTE at $85 \%$ load.

the higher the fuel additive addition the shorter the ignition delay period. At the same time, the peak HRR is reducing, resulting in a smoother, less violent combustion and more similar to diesel profile. However, it can still be observed the two-phase combustion for the PPO 75 fuel additive blends due to the longer ignition delay period which enhances the premixed combustion portion. It is worth mentioning at this point that the engine's noise was better as the ratio of the fuel additive was increasing. The knock effect is a very important factor for the engine's operational life. The reduction of the knock effect achieves the increase of the engine's operational life. In order to eliminate the knock effect the addition of a proper cetane number improver seems to be unavoidable in the case of PPO 75.

Figure 10 depicts the variation of BTE for diesel, PPO 75, PPO 75 1:80, and PPO $751: 40$ at 85\% load. According to the figure, there is an improvement of the BTE by increasing the amount of the fuel additive. More specifically, the BTE increases from $32.8 \%$ to $33.2 \%$ with a blend ratio of $1: 80$

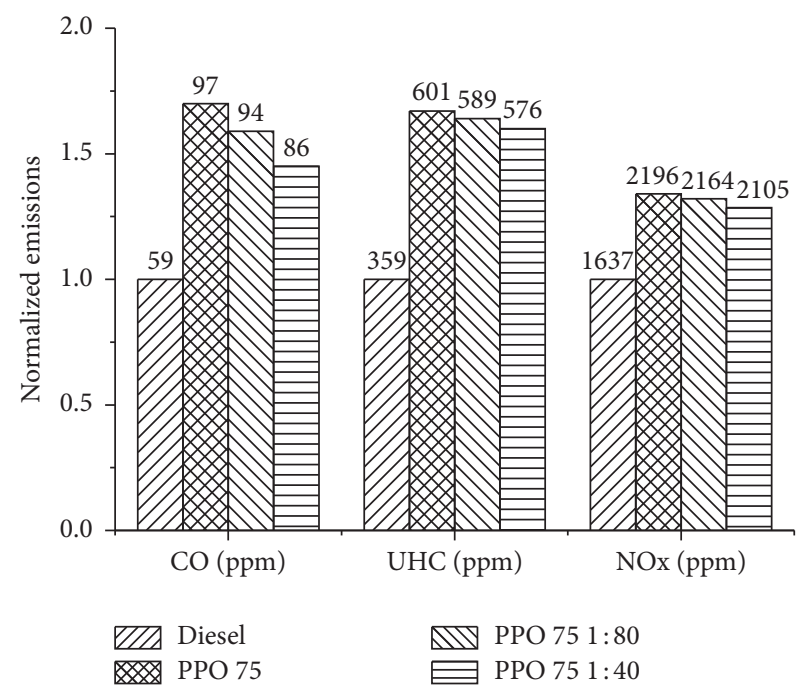

Figure 11: Normalized values of CO, UHC, and NOx emissions.

and to $33.5 \%$ with a ratio of $1: 40$ fuel additive. This result indicates that the earlier start of combustion improves the conversion of heat (released from the fuel) to kinetic energy on the pistons. There is still room for improvement which is possible to be covered by adding a dedicated cetane number fuel additive.

Figure 11 presents the normalized values of the carbon monoxide (CO), unburned hydrocarbons (UHC), and nitrogen oxides (NOx) emissions for the engine operation on diesel, PPO 75, PPO 75 1:80, and PPO 75 1:40. It can be observed from the experimental results that the $\mathrm{CO}$ emissions decrease with the addition of the fuel additive, but they still remain much higher in comparison with diesel. This result indicates that the fuel additive enhances the combustion performance and more carbon atoms are able to oxidize and form $\mathrm{CO}_{2}$. Moreover, the shorter ignition delay period results in less impingement of the fuel on the cylinder walls and local fuel-rich zones. As regards the UHC emissions, it can be noticed from Figure 11 that there is a slight decrease with the addition of the fuel additive, but UHC emissions are still significantly higher than diesel operation. The shorter ignition delay period reduces the amount of fuel that impinges on the cylinder walls; therefore, less rich-fuel regions are developed. Finally, according to the experimental results presented in Figure 11, NOx emissions do not seem to get affected significantly by the addition of the fuel additive. Maybe this is a result of two different processes which result in the same total amount of NOx emission. The addition of the fuel additive reduces the ignition delay period resulting in less homogeneous air-fuel mixing (lower in-cylinder temperatures and lower NOx). At the same time the fuel additive improves the combustion even in rich-fuel zones resulting in elevated in-cylinder temperatures and $\mathrm{NOx}$ emissions. Consequently, the total amount of NOx emissions remains the same. 


\section{Conclusions}

An experimental investigation was carried out to analyse and understand the combustion, performance, and emission characteristics of a diesel engine running on advanced injection timing and on standard injection timing with the addition of a fuel additive on oil which derives from the pyrolysis of waste plastics. The following conclusions can be drawn from the test results:

(i) The engine was able to operate at AIT on PPO 75 at $75 \%$ load but with longer ignition delay, higher cylinder peak pressure, and higher heat release rate in comparison with the PPO 75 SIT operation.

(ii) The addition of the fuel additive reduces the ignition delay period, cylinder peak pressure, and peak heat release rate. As a result, the brake thermal efficiency, $\mathrm{CO}, \mathrm{UHC}$, and NOx emissions are all improved.

(iii) The engine's thermal efficiency decreases with the AIT and all measured emissions, including CO, UHC, and NOx, increase with AIT. The spray test revealed that the PPO spray has a longer tip penetration, which explained why AIT is not a preferable solution.

The testing results suggest that for both long-term and shortterm operation, the AIT is not preferable as the engine performance declines. As regards to the fuel additive engine testing, the results suggest that the use of a dedicated cetane number fuel additive would achieve even better combustion performance (similar to diesel).

\section{Nomenclature}

PPO 75: $75 \%$ plastic pyrolysis oil $+25 \%$ diesel fuel

SIT: $\quad$ Standard injection timing

AIT: Advanced injection timing

bTDC: Before top dead centre

NOx: Nitrogen oxides

PM: Particulate matter

CO: $\quad$ Carbon monoxide

$\mathrm{CO}_{2}$ : Carbon dioxide

UHC: Unburned hydrocarbon

LHV: Lower heating value

BMEP: Brake mean effective pressure

HRR: Heat release rate

$\varphi$ : $\quad$ Equivalence ratio

BTE: Brake thermal efficiency.

\section{Competing Interests}

The authors declare that there is no conflict of interests regarding the publication of this paper.

\section{Acknowledgments}

The authors sincerely thank Thermitech Solutions Ltd and UK Engineering and Physical Sciences Research Council (EP/K036548/2) for the support to conduct this research.

\section{References}

[1] M. Mani, C. Subash, and G. Nagarajan, "Performance, emission and combustion characteristics of a DI diesel engine using waste plastic oil," Applied Thermal Engineering, vol. 29, no. 13, pp. 2738-2744, 2009.

[2] C. Wongkhorsub and N. Chindaprasert, "A comparison of the use of pyrolysis oils in diesel engine," Energy and Power Engineering, vol. 5, pp. 350-355, 2013.

[3] M. Mani, G. Nagarajan, and S. Sampath, "An experimental investigation on a di diesel engine using waste plastic oil with exhaust gas recirculation," Fuel, vol. 89, no. 8, pp. 1826-1832, 2010.

[4] R. Guntur, D. Kumar, and V. K. Reddy, "Experimental evaluation of a diesel engine with blends of diesel-plastic pyrolysis oil," International Journal of Engineering Science and Technology, vol. 6, pp. 5033-5040, 2011.

[5] M. Mani, G. Nagarajan, and S. Sampath, "Characterisation and effect of using waste plastic oil and diesel fuel blends in compression ignition engine," Energy, vol. 36, no. 1, pp. 212-219, 2011.

[6] J. Pratoomyod and K. Laohalidanond, "Performance and emission evaluation of blends of diesel fuel with waste plastic oil in a diesel engine," International Journal of Engineering Science and Technology, vol. 2, pp. 57-63, 2013.

[7] C. Güngör, H. Serin, M. Özcanl, S. Serin, and K. Aydin, "Engine performance and emission characteristics of plastic oil produced from waste polyethylene and its blends with diesel fuel," International Journal of Green Energy, vol. 12, no. 1, pp. 98105, 2015.

[8] V. K. Kaimal and P. Vijayabalan, "A detailed study of combustion characteristics of a DI diesel engine using waste plastic oil and its blends," Energy Conversion and Management, vol. 105, pp. 951-956, 2015.

[9] M. Mani and G. Nagarajan, "Influence of injection timing on performance, emission and combustion characteristics of a DI diesel engine running on waste plastic oil," Energy, vol. 34, no. 10, pp. 1617-1623, 2009.

[10] A. Sharma and S. Murugan, "Combustion, performance and emission characteristics of a di diesel engine fuelled with nonpetroleum fuel: a study on the role of fuel injection timing," Journal of the Energy Institute, vol. 88, no. 4, pp. 364-375, 2015.

[11] A. K. Wamankar and S. Murugan, "Effect of injection timing on a di diesel engine fuelled with a synthetic fuel blend," Journal of the Energy Institute, vol. 88, no. 4, pp. 406-413, 2015.

[12] J. Devaraj, Y. Robinson, and P. Ganapathi, "Experimental investigation of performance, emission and combustion characteristics of waste plastic pyrolysis oil blended with diethyl ether used as fuel for diesel engine," Energy, vol. 85, pp. 304-309, 2015.

[13] S. Hariharan, S. Murugan, and G. Nagarajan, "Effect of diethyl ether on Tyre pyrolysis oil fueled diesel engine," Fuel, vol. 104, pp. 109-115, 2013.

[14] I. Kalargaris, G. Tian, and S. Gu, "Combustion, performance and emission analysis of a DI diesel engine using plastic pyrolysis oil," Fuel Processing Technology, vol. 157, pp. 108-115, 2017.

[15] J. B. Heywood, Internal Combustion Engine Fundamentals, McGraw Hill, New York, NY, USA, 1988.

[16] G. Greeves, I. M. Khan, C. H. T. Wang, and I. Fenne, "Origins of hydrocarbons emissions from diesel engines," SAE Technical Paper 770259, 1977.

[17] S. Mendez, J. T. Kashdan, B. Thirouard, G. Bruneaux, and F. Vangraefschepe, "Formation of unburned hydrocarbons in low 
temperature diesel combustion," SAE Technical Paper 2009-012729, 2009.

[18] H. Semerjian and A. Vranos, "NOx formation in premixed turbulent flames," Symposium (International) on Combustion, vol. 16, no. 1, pp. 169-179, 1977.

[19] J. Mo, C. Tang, J. Li, L. Guan, and Z. Huang, "Experimental investigation on the effect of n-butanol blending on spray characteristics of soybean biodiesel in a common-rail fuel injection system," Fuel, vol. 182, pp. 391-401, 2016. 


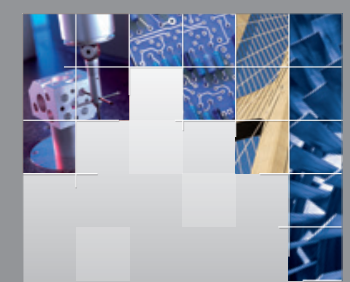

\section{Enfincering}
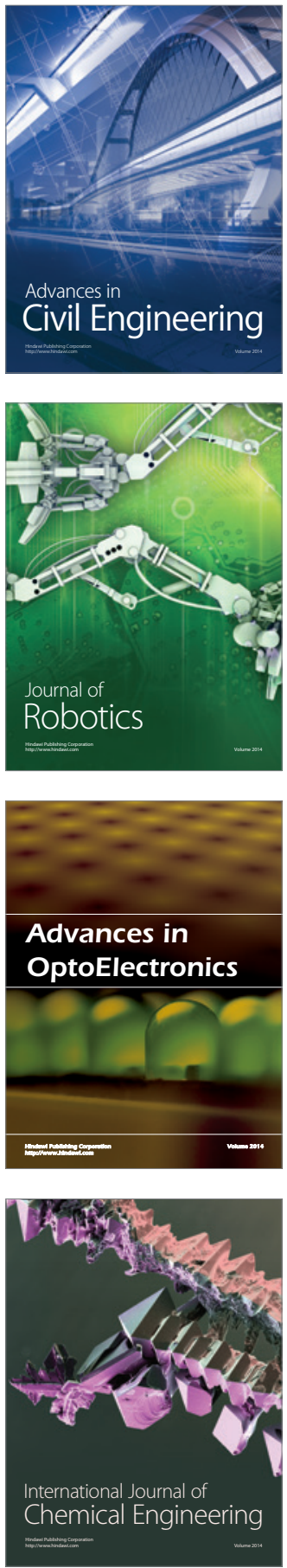

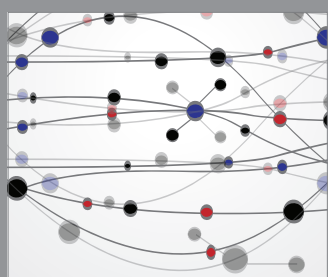

The Scientific World Journal

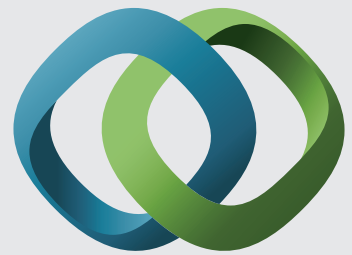

\section{Hindawi}

Submit your manuscripts at

https://www.hindawi.com
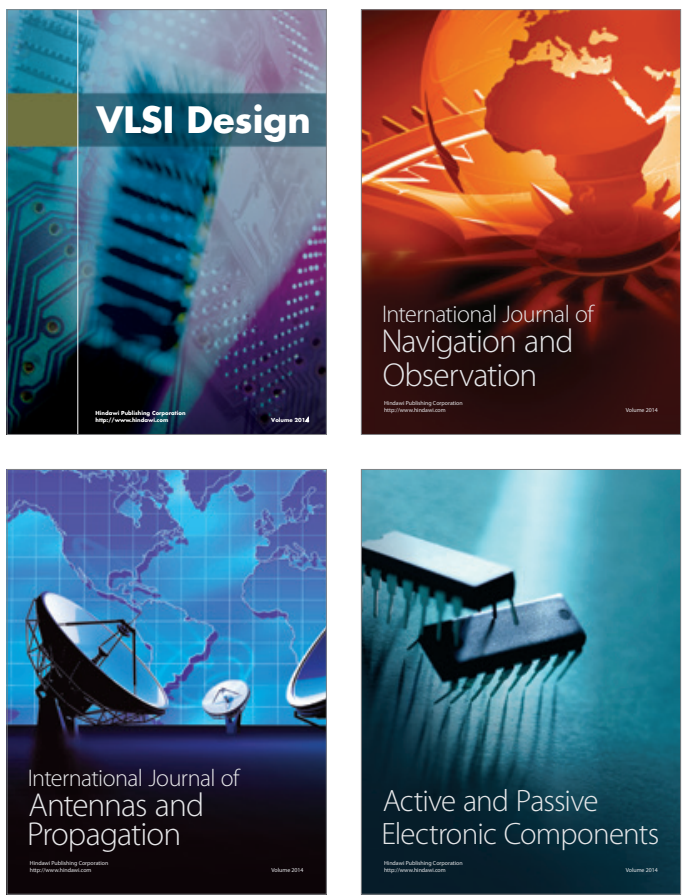
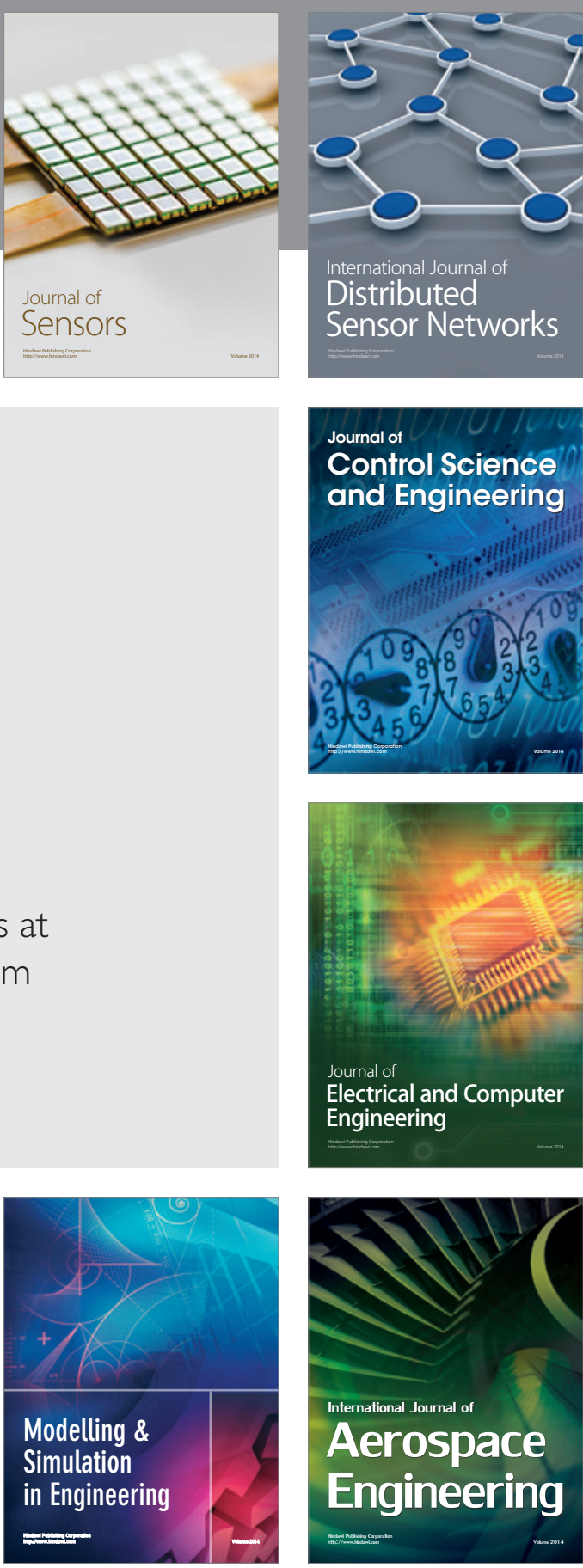

International Journal of

Distributed

Sensor Networks

$-$

Joumal of

Control Science

and Engineering
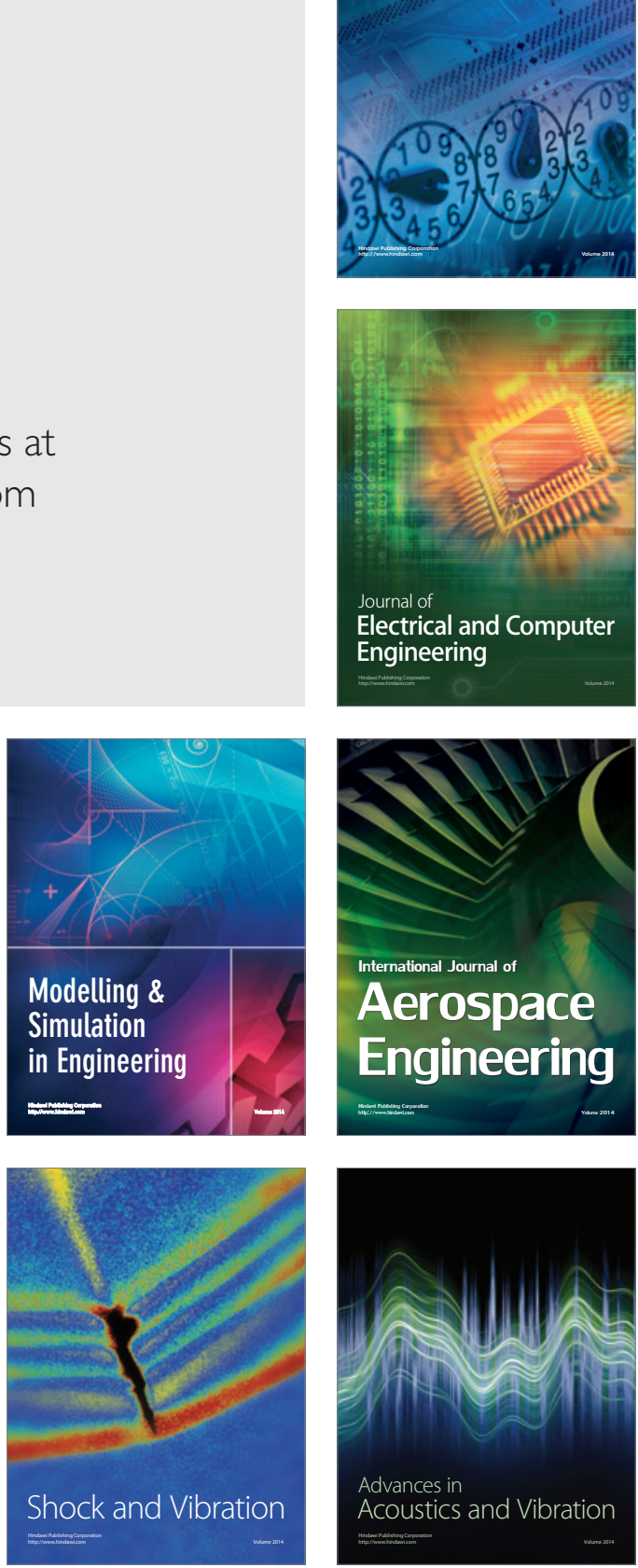